\title{
LAS FUNCIONES PRAGMÁTICAS Y LA ESTRATIFICACIÓN SOCIOLINGÜÍSTICA DE LAS PARTÍCULAS DISCURSIVAS PO Y PUES EN EL HABLA DE SANTIAGO DE CHILE ${ }^{1}$
}

\section{PRAGMATIC FUNCTIONS AND SOCIOLINGUISTIC STRATIFICATION OF THE DISCURSIVE PARTICLES PO AND PUES IN THE SANTIAGO, CHILE'S SPEECH}

\author{
Josefa Manni \\ Universidad de Chile \\ josefamanni.uchile@gmail.com \\ Abelardo San Martín \\ Universidad de Chile \\ asmartin@uchile.cl
}

\section{Resumen:}

En este trabajo se analizan los valores pragmáticos y la distribución social de las partículas po y pues en un corpus de 120 entrevistas sociolingüísticas de hablantes santiaguinos. Para este propósito, por un lado, se identifican las funciones que cumplen dichas partículas en las entrevistas y, por otro, se correlacionan las variables sociales género, edad y grupo socioeconómico de los informantes con su empleo en el corpus. Los resultados muestran que la posición de ambas partículas determina sus valores y que po tiende a combinarse con otras unidades para cumplir funciones diversas; asimismo, po se emplea con mucha más frecuencia que pues y la asociación de los factores sociales con el uso de po es desigual, ya que es más intensa en los grupos socioeconómicos medio bajo y bajo.

Palabras clave: po, pues, partículas discursivas, funciones pragmáticas, estratificación sociolingüística, español oral de Santiago de Chile.

\begin{abstract}
:
In this paper the pragmatic values and the social distribution of the po and pues particles are analyzed in a corpus of 120 sociolinguistic interviews of Santiago speakers. For this purpose, on the one hand, the functions that these particles fulfill in the interviews are identified and, on the other, the social variables gender, age and socioeconomic group of the informants are correlated with their use in the corpus. The results show that the position of both particles determines their values and that po tends to combine with other units to fulfill different functions; likewise, po is used much more frequently than pues, and the association of social factors with the use of po is unequal, since it is more intense in lower middle and lower socioeconomic groups.

\footnotetext{
${ }^{1}$ Este estudio forma parte del proyecto FONDECYT Regular №1161422, "Los marcadores del discurso en el español hablado en Santiago de Chile: análisis pragmático y sociolingüístico". Se sintetizan, reformulan y amplían aquí los principales hallazgos de la tesis de licenciatura de Josefa Manni, "Análisis pragmático y sociolingüístico de las funciones de po y pues como marcadores del discurso en el habla de Santiago de Chile”, investigación dirigida por Abelardo San Martín, en el marco del proyecto antes mencionado.
} 
Key words: po, pues, discursive particles, pragmatic functions, sociolinguistic stratification, oral Spanish from Santiago (Chile).

Recibido: 06 de abril de 2021

Aceptado: 05 de junio de 2021

\section{INTRODUCCIÓN}

\subsection{Naturaleza, objetivos y alcance de estudio}

Es un hecho muy llamativo, además de comentado en diferentes medios, la intensidad con la que se emplea la partícula po, variante vernácula monoptongada de pues, en la variedad chilena de la lengua española, a tal punto que se la ha descrito como una particularidad de nuestro dialecto (San Martín, Marcadores discusivos). A raíz de ello, en este artículo hemos querido abordar su empleo en contraste con la variante estándar pues, desde los puntos de vista pragmático y sociolinguístico. Combinamos aquí, por lo tanto, herramientas provenientes de la pragmática del discurso oral y de la sociolingǘstica variacionista; encuadre analítico sociopragmático que ya hemos aplicado en varios trabajos anteriores sobre el empleo de los marcadores del discurso en el español chileno (San Martín, Marcadores interrogativos, Marcadores de reformulación, Marcadores discusivos; Panussis y San Martín, Lewis y San Martín, González y San Martín, Sandoval y San Martín). Nuestro objetivo general es analizar las funciones pragmáticas y la estratificación sociolingüística de las partículas po y pues en el habla de Santiago de Chile. Consecuentemente, nuestros objetivos específicos son: 1) identificar las funciones pragmáticas que ejercen ambas partículas, considerando su posición en el enunciado y sus combinaciones más frecuentes con otras partículas, locuciones o adverbios y 2) determinar si existe alguna relación entre ambas partículas y los factores sociodemográficos: género, edad y grupo socioeconómico del hablante. Nuestras hipótesis son que: 1) la posición de po y pues diferencia los valores de ambas partículas, 2) en contraste con pues, po se combina con otros formantes para cumplir diferentes funciones, 3) po se emplea mucho más que pues en la muestra y 4) aunque el empleo de po está muy extendido en el español santiaguino (y por extensión chileno), su distribución en los factores sociales de los informantes es desigual. 


\section{MARCO TEÓRICO}

\subsection{El estudio de po y pues como partículas discursivas en español}

Los marcadores discursivos, también llamados partículas discursivas, son unidades invariables y periféricas que orientan la interpretación de los enunciados en el discurso (Portolés). Corresponden a una categoría compleja cuya denominación, delimitación y clasificación ha recibido múltiples aproximaciones y su estudio en español ha sido objeto de un creciente interés en los últimos años (Loureda y Acín). En la actualidad, como señalan dichos autores, a efecto de incluir otros mecanismos con función enunciativa como los modalizadores, se ha popularizado también el concepto de partícula discursiva ${ }^{2}$. En este estudio hemos optado por el término "partícula" para denominar a po y pues, debido a que la función principal que analizaremos está en el marco de la modalización discursiva; sin embargo, como veremos más adelante, también pueden cumplir otras funciones en los ámbitos de la conexión y la formulación del discurso, en cuyo caso se comportan propiamente como "marcadores". Por otro lado, aunque en diferentes trabajos se ha abordado la clasificación y las funciones de las partículas po y pues, tanto a nivel textual como conversacional, la primera ha concitado menos atención que la segunda, debido a que, en contraste con el estatus panhispánico de pues, po constituye una particularidad dialectal del español chileno. Sin embargo, hasta donde sabemos, no existen estudios monográficos sobre las funciones específicas de po en el español de Chile, de modo que solo se lo ha descrito en términos generales, en conjunto con otros marcadores.

En cuanto a los trabajos de alcance más general, Martín Zorraquino y Portolés señalan que pues es un estructurador comentador muy frecuente en el discurso oral que "se sitúa en la posición inicial del miembro que introduce [...] y lo presenta como un comentario nuevo e informativamente valioso con respecto del discurso que lo precede" (4083). Según los mismos autores, otra función de pues, en posición no inicial, es la de conector consecutivo que "remite a un miembro del discurso anterior y presenta el miembro del discurso en el que se encuentra como su consecuente" (Martín Zorraquino y Portolés

\footnotetext{
$2 \mathrm{Al}$ respecto, es sintomático que una de las principales obras lexicográficas de este tipo de recursos pragmáticos incluya el término partícula discursiva en su título (Briz et al.).
} 
Artículo. Josefa Manni, Abelardo San Martín. "Las funciones programáticas y la estratificación sociolingüística de las partículas po y pues en el habla de Santiago de Chile"

4099). También existen las partículas pues bien y así pues que funcionan como unidades gramaticalizadas con las mismas funciones antes señaladas. Por un lado, pues bien es un estructurador comentador, que va en posición inicial y seguido de pausa, y mediante el cual "con el miembro que lo precede, se propone un estado de cosas que, una vez asumido por el interlocutor, permitirá el comentario en que consiste el segundo miembro" (Martín Zorraquino y Portolés 4084); por otro, así pues es un conector consecutivo que introduce un miembro del discurso como consecuente "que se obtiene después de un razonamiento a partir de otro miembro que actúa como antecedente" (4100). A este respecto también cabe señalar que para Briz et al. pues presenta el miembro del discurso que introduce como una continuación que transmite información nueva.

Por otra parte, Martín Zorraquino clasifica a pues como una conjunción coordinante, es decir, se ubica entre los elementos que relaciona, que expresa causa; además, "introduce un comentario remático: información nueva en relación con lo precedente, ya sea implícito o explícito" (117). De acuerdo con esta autora, la partícula pues ha sufrido un leve proceso de gramaticalización, por lo tanto, forma parte de los marcadores del discurso y funciona como partícula informativa (remática) "con estatuto coincidente, en cuanto a que opera en el nivel de la estructura informativa, al de los adverbios adjuntos enfocantes (incluso, también, etc.), ya que, aunque tiende a aparecer en posición proclítica, puede comparecer tras la última palabra de un enunciado" (Martín Zorraquino 116). Por último, destaca que en Chile pues se usa tanto que se reduce hasta convertirse en una especie de holofrase (esto es, $\left.p^{\prime}\right)$, de modo similar a lo que ocurre con otras interjecciones.

Por lo que refiere a los estudios con muestras del español de Chile, Poblete (Marcadores en la construcción y Marcadores de más alta frecuencia) identifica los marcadores discursivos más frecuentes en el habla de Valdivia, entre los que destaca a po como marcador modal cuya función es apoyar una opinión en posición final del enunciado, en particular, cuando se da en las siguientes combinaciones: sí po, no más po, también po y nada más po. En así po se comporta como modalizador de evidencia para atenuar o enfatizar y en no sé po es un marcador exclusivamente atenuativo. Por otro lado, Pilleux analiza la función del marcador discursivo no sé po en el discurso oral de Temuco y señala que se trata de una unidad léxica autónoma que se ubica en diferentes posiciones del discurso (inicial, media o final). Para este autor no sé po es un marcador polisémico, ya que 
cumple diferentes funciones dentro del discurso oral: reformulación como sinónimo de $O$ sea, es decir y por ejemplo; atenuación como sinónimo de no compromiso, desacuerdo velado; atenuación de punto de vista, evasión, autojustificación y duda. Por su parte, Pons y Samaniego analizan los marcadores más frecuentes y sus funciones en el habla culta espontánea y semi-espontánea de diferentes grupos etarios de Santiago. Según sus resultados, $p o$ y sus respectivas variantes ( $p$ y $p u$ ) corresponden al grupo de marcadores de término de enunciado o intervención y cumplen la función de cierre de un enunciado o turno, además, pueden aparecer solos o combinados con algún apelativo seudo-vocativo, adquiriendo un valor finalizador. Con respecto a los factores sociales edad y género, concluyen que po y sus variantes se emplean con mayor frecuencia en el grupo juvenil, sin que existan diferencias entre mujeres y hombres.

Para finalizar, con respecto a perspectivas contrastivas intralingüísticas, Fuentes et al. analizan las funciones de pues y sus variantes en tres variedades de español: Quito (Ecuador), Sevilla (España) y Santiago (Chile) y concluyen que se pueden identificar diferencias en el contraste entre dichas regiones dialectales. Específicamente, en Sevilla, en turno inicial, pues introduce un turno reactivo como conector; en el turno medio, actúa como conector continuador, anafórico y elemento fático y, en el acto final, opera como un conector dispositivo de cierre y como operador de apoyo de su acompañante. Por otro lado, pues y sus variantes actúan como conectores de dispositivo de cierre y como operadores de apoyo de sus acompañantes en Quito y Santiago. Dichas autoras señalan que pues y su variante fonética po funcionan como marcadores de turno final con la función principal de reforzar lo que se ha dicho o comentado anteriormente; además, siguiendo a Cepeda y Poblete destacan las cualidades prosódicas en la realización de pues que se asocian con la función de refuerzo que es clave para los marcadores de turno final que manifiestan cierta curva melódica que transmite conclusividad y seguridad (Fuentes et al.).

\section{METODOLOGÍA}

\subsection{Corpus y muestra}

El corpus que sirvió de base para nuestro trabajo comprende 120 entrevistas sociolingüísticas pertenecientes al corpus del grupo de Estudio Sociolingüístico del Español 
Artículo. Josefa Manni, Abelardo San Martín. "Las funciones programáticas y la estratificación sociolingüística de las partículas po y pues en el habla de Santiago de Chile"

de Chile $(\mathrm{ESECH})^{3}$, que considera la población constituida por mujeres y hombres de la Región Metropolitana mayores de 20 años. El cuestionario se aplicó a una muestra por cuotas con afijación uniforme, en la que se divide a la población en estratos o categorías y se asigna una cuota a cada uno de los distintos estratos ${ }^{4}$. La transcripción de las entrevistas antes señaladas fue exhaustivamente revisada, sin excluir ninguna de las secciones del instrumento.

\subsection{Procedimiento de estratificación social}

Para la estratificación de los sujetos que conforman la muestra del estudio, se empleó el sistema de adscripción de estatus social empleado en ESECH, que consiste en un procedimiento basado en determinados estudios acerca de la realidad socioeconómica chilena y mediante el cual se asigna un puntaje a los informantes (indicado entre paréntesis, a continuación), de acuerdo con las siguientes variables: a) nivel educacional (3), b) profesión u ocupación (2) y c) comuna de residencia (1). A partir de la asignación de los mencionados puntajes, se definieron cuatro grupos socioeconómicos, definidos según los rangos siguientes: a) Medio alto (MA): 42-36, b) Medio (M): 35-27, c) Medio bajo (MB): 26-18 y d) Bajo (B): 17-6

\subsection{Procedimiento analítico}

Nuestro análisis de las partículas po y pues consideró la determinación de sus respectivas frecuencias de ocurrencia en las entrevistas que conforman la muestra.

\footnotetext{
${ }^{3}$ El ESECH es un grupo de investigación del Departamento de Lingüística de la Facultad de Filosofía y Humanidades de la Universidad de Chile coordinado por Abelardo San Martín. Pueden consultarse las actividades de este grupo de estudio en la siguiente dirección electrónica: https://estudiosociolinguistico.uchile.cl/

${ }^{4}$ Las entrevistas fueron realizadas a hablantes santiaguinos, entre 2005 y 2011, por los estudiantes en la asignatura de Sociolingüística de los programas de Licenciatura en Lengua y Literatura Hispánicas y Licenciatura en Lengua y Literatura Inglesas de la Universidad de Chile. En la situación de entrevista, los entrevistadores debían tratar de superar la "paradoja del observador" consiguiendo, de esta forma, una muestra significativa de discurso natural grabado (estilo vernáculo) de hablantes representativos de la comunidad de habla en estudio (Labov).

${ }^{5} \mathrm{El}$ intervalo de cada rango responde a la mayor coincidencia con los puntajes que han establecido los estudios sociológicos y de mercado para la clasificación de estratos socioeconómicos, aunque con las debidas adaptaciones, puesto que en esta muestra no se incluyen ni el grupo de la extrema pobreza ni el de la extrema riqueza. Para mayores detalles del sistema de estratificación y el corpus puede consultarse la página electrónica del grupo de estudio antes señalada.
} 
Asimismo, de modo coherente con nuestros objetivos, se observó la incidencia de los siguientes factores sociodemográficos de los hablantes: género, edad y grupo socioeconómico. El análisis estadístico atendió a dos niveles de observación: a) en términos descriptivos, según frecuencias absolutas y porcentajes de frecuencia y b) en términos interpretativos o inferenciales, con base en la comparación entre las medias o tendencias centrales de las partículas analizadas ${ }^{6}$.

\section{PRESENTACIÓN Y ANÁLISIS DE LOS RESULTADOS}

\subsection{Análisis pragmático}

En este apartado presentaremos los resultados del análisis pragmático de las funciones discursivas generales de po y pues, así como de los valores particulares de las combinaciones sintagmáticas de la primera de estas partículas.

\subsubsection{Funciones generales de po y pues}

Entre las funciones generales de po y pues podemos distinguir una exclusiva de esta última y otras que son compartidas por ambas partículas. En primer lugar, daremos cuenta de la función exclusiva de pues para continuar con las funciones compartidas que son, de hecho, las que aquí más nos interesan, dada su incidencia en el corpus analizado.

\subsubsection{Función exclusiva de pues}

En nuestro corpus relevamos algunos casos de pues como conector causal a inicio de acto, cuya función es introducir una causa y que es conmutable por porque. Con respecto a dicha función, Fuentes (291) señala que "introduce una consecuencia o conclusión del enunciado previo; aparece en razonamientos y conecta enunciados”. Ejemplos:

\footnotetext{
${ }^{6}$ Por lo que se refiere a la descripción de los procedimientos estadísticos aplicados, en este trabajo seguimos las sugerencias e indicaciones de Hernández Campoy y Almeida. El paquete estadístico al que hemos recurrido para la estadística inferencial es el SPSS (Statistical Package for the Social Sciences), versión 15.0 para Windows, específicamente, la prueba Análisis de varianza ANOVA. En atención a que la distribución de los datos, en algunos casos, pudiera ser anormal, se complementará dicho análisis con su análogo de tipo no paramétrico, esto es, Anova de Kruskal-Wallis. En ambos casos, el grado de significación se definirá en el $5 \%$, según el cual $\mathrm{p}=<0,05$ será estadísticamente significativo.
} 
Artículo. Josefa Manni, Abelardo San Martín. "Las funciones programáticas y la estratificación sociolingüística de las partículas po y pues en el habla de Santiago de Chile"

1) cuando me puse a pololear/ estaba feliz/ no estaba/ así como/ sí feliz/ pues igual ha sido de repente cuando tus logros/ en la universidad cuando pasas un año/ pero no son momentos de felicidad así cúlmine/ porque igual me ha costado [...] (MB III M093) ${ }^{7}$

2) [...] y yo iba con lentes de contacto así furor po// entonces la envidia igual era grande porque "oh que usted es linda" no sé po/ cuestiones así/ o hasta un profesor una vez me tenía envidia// que era gay/ eh pues yo iba con lentes de contacto [...] (MB III M093)

Se trata de una función exclusiva de pues que se da solo en posición inicial de acto, es decir, nunca es desempeñada por po y, además, en posición final pues se comporta de modo semejante a po. Con todo, los ejemplos de la función de conexión causal mediante pues son muy infrecuentes en el corpus.

\subsubsection{Funciones compartidas de po y pues}

La función principal de las partículas po y pues que verificamos en el corpus, sobre todo, de la primera, es la función modal de intensificación. Para Briz (Otra vez) la intensificación como estrategia pragmática busca lograr una mayor eficacia y efectividad en el discurso, por lo que se relaciona con conceptos como realce, intensidad, refuerzo y maximización de la fuerza ilocutiva y parte del concepto de reafirmación, definido como "reforzar una postura o una condición" (DLE s.v. reafirmación). Se subclasifica en tres funciones específicas:

\footnotetext{
${ }^{7}$ Respecto de la transcripción de los ejemplos, creemos necesario indicar las siguientes convenciones gráficas: 1) cuando corresponda a ejemplos de mayor extensión, $\mathrm{E}=$ entrevistador e $\mathrm{I}$ = informante; 2) como se trata de variables no fonéticas y, por lo tanto, la pronunciación no es el foco de nuestro análisis, el texto correspondiente a cada ejemplo se transcribe en ortografía convencional, incluidos los acentos gráficos; 3) con el propósito de no desnaturalizar demasiado la representación del habla chilena, se ha conservado la manifestación gráfica de determinados usos característicos del español hablado en Chile, como el uso del voseo paradigmático con elisión de $-\mathrm{s}$, por ejemplo, estái, soi, viví (estáis, sois, vivís con valor de segunda persona del singular, tú) y el empleo de marcadores del discurso, como po (pues), ¿cachái? (¿entiendes?); 4) para la mejor comprensión de los ejemplos incluidos en este estudio, se ha suprimido el sistema de etiquetas pertenecientes al Standard Generalized Markup Language (SGML) contenidas en el Text Encoding Initiative (TEI), que se emplea en la transcripción de las entrevistas de ESECH, excepto las pausas, que se señalan con 1. Los marcadores analizados se presentarán siempre en letra cursiva. Al final de cada ejemplo, se indica, entre paréntesis, el código del informante, según las siguientes convenciones: grupo socioeconómico $(\mathrm{MA}=$ medio alto, $\mathrm{M}=$ medio, $\mathrm{MB}=$ medio bajo, $\mathrm{B}=$ bajo), grupo etario ( $\mathrm{III}=$ adultos mayores de 55 años y más, $\mathrm{II}=$ sujetos adultos de edad intermedia entre 35 y 54 años y $\mathrm{I}=$ hablantes jóvenes de entre 20 y 34 años) y sexo (M= mujer y $\mathrm{H}=$ hombre). A continuación del sexo se señala el número correlativo del sujeto en el corpus.
} 
a) Auto-reafirmación: consiste en un recurso utilizado por el hablante para reafirmar su postura u opinión e intensificar la narración de sus experiencias. Ejemplos:

3) eh/ no/ una vez/ en el pasaje se metieron a robar po/ después de las [...]/ las puertas abiertas ¿cachái?/ se metieron como a dos casas/ tres casas más o menos/ se robaron los/ los juguetes de los pendejos huevón/ que les habían regalado recién/ y eso po $(\mathrm{B} \mathrm{I} \mathrm{H} 005)$

4) I: entonces a mí me dio vergüenza por el caballero po/ que pucha justo él me avisó y me pasó una hoja de diario para que yo me tapara/ andaba haciendo unos trámites y tenía que devolverme a mi casa po/ eso fue $\mathrm{po} / \mathrm{siempre}$ me acuerdo (B III M042)

5) voy llegando a ellos/ los compadres sacan sus herramientas pues huevón/ y yo/ no sé pues/ saco las manos y les pego así/ ¡pa! y paso pues entre medio/ recibo unos combos por las costillas unas patadas/ pero pasé pues huevón/ y corrí otra vez pues huevón y me zafé nuevamente pues huevón/ llegué hasta ahí hasta la plaza (B II H019)

En algunos casos ambas partículas se ubican en medio del turno, debido a que también actúan como continuadores y cumplen una función fática. En otras ocasiones se ubican al final de acto como recurso de cierre para ceder el turno al interlocutor. También cumplen la función de intensificar la narración del hablante, dándole mayor viveza y emotividad a la historia relatada.

b) Alo-reafirmación: cumple la función de reforzar el acuerdo con el interlocutor, lo que muestra mayor complicidad y empatía. También ayuda a reforzar la imagen social del otro. Ejemplos:

6) I: y ¿qué le iba a hacerle? po E: perdió ya po I: claro po/ sí (B II H021)

7) I: [...] pero uno que cuando tiene cuarenta/ cuarenta y seis o cuarenta y cinco años no/ ya de sesenta años para arriba ayudan/ ayudan a las viejitas E: claro I: claro po (B III M043)

8) E: suerte igual entonces pues I: sí pues no cualquiera la tiene pues huevón (B II H019) 
Artículo. Josefa Manni, Abelardo San Martín. "Las funciones programáticas y la estratificación sociolingüística de las partículas po y pues en el habla de Santiago de Chile"

Como podemos advertir en los ejemplos, estas partículas ayudan a reforzar el acuerdo frente a una aseveración, opinión o pregunta enunciada por el interlocutor, lo que fomenta una mayor complicidad con el otro y una reafirmación de su imagen.

c) Contra-reafirmación: se relaciona en el plano argumentativo con la reafirmación contraria a lo dicho por el interlocutor u otras personas. Ejemplos:

9) E: no me acuerdo// no vengái con atados/ teníai que haberla pasado antes esta cuestión para haberla I: ¡no po! sí tení que pensar así po/ ¿cómo vai a estar tan destruido huevón? (MB I H050)

10) E: y al final ¿le robaron la plata/ o no? I: ¡ah ya! no pues mi amor/ si no le conté/ ¡ya! dije yo bueno entonces esperé como le digo/ se perdió la liebre abro el chauchero y estaba la plata ahí/ toda/ así tal cual (MB III M093)

Se puede percibir en los ejemplos que po y pues intensifican el desacuerdo, reforzando al adverbio de negación no. El interlocutor emite una aseveración o pregunta, frente a lo cual, si el hablante no está de acuerdo o quiere contradecirlo, refuerza su intención mediante estas partículas, añadiendo una fuerza ilocutiva a la negación que puede llegar a dañar la imagen del otro o la propia. Es importante mencionar que al ser una entrevista sociolingüística no se producen muchas instancias de confrontación o desacuerdo, ya que el entrevistador más que exponer su propia opinión se encarga de estimular o motivar la participación del informante mediante preguntas que sean de su interés.

La siguiente tabla resume los resultados de las funciones generales de las partículas aquí analizadas: 


\begin{tabular}{|c|c|l|}
\hline Posición & Partícula & \multicolumn{1}{|c|}{ Función } \\
\hline acto inicial & pues & $\begin{array}{l}\text { Función causal: introduce una } \\
\text { causa y conecta enunciados. }\end{array}$ \\
\hline turno medio & po y pues & $\begin{array}{l}\text { Operan como continuadores e } \\
\text { intensificadores. También } \\
\text { poseen una función fática. }\end{array}$ \\
\hline acto final & po y pues & $\begin{array}{l}\text { Actúan como un recurso de } \\
\text { cierre y de apoyo. En un turno } \\
\text { reactivo apoyan una respuesta } \\
\text { afirmativa o contraria. }\end{array}$ \\
\hline
\end{tabular}

Tabla 1: Resumen de los resultados de las funciones generales de po y pues en el corpus

\subsubsection{Funciones particulares de las combinaciones sintagmáticas de po}

Un hallazgo que destaca, en los materiales que analizamos, es la frecuencia con la que la partícula po se combina con otras partículas, adverbios, locuciones y vocativos, unidades a las que denominamos "combinaciones sintagmáticas" y que es una particularidad que no se aplica a pues con la misma recurrencia. Las combinaciones más frecuentes en el corpus fueron: no sé po, nada po, sí po, ya po, no po, no más po, claro po y po huevón. Como se ve, en casi todas, menos en la última, po se ubica en posición final a modo de coletilla, excepción hecha de po huevón donde precede a este vocativo. A nuestro juicio, estas combinaciones son el resultado de un proceso de gramaticalización, esto es, "un proceso mediante el cual una forma léxica o construcción, en contextos pragmáticos y morfosintácticos específicos, asume una función gramatical, o bien una entidad o construcción ya gramatical adquiere una función aún más gramatical" (Company 29). En este sentido, estas combinaciones se comportan como bloques discursivos con funciones diferentes e, incluso, pueden llegar a ser polifuncionales por lo que actúan como marcadores discursivos complejos. Así, si bien en cada caso la subfunción de po es intensificadora, el resultado global de cada combinación puede ser una función distinta, más abarcadora y que es, precisamente, la que procesa el o la hablante. 
Artículo. Josefa Manni, Abelardo San Martín. "Las funciones programáticas y la estratificación sociolingüística de las partículas po y pues en el habla de Santiago de Chile"

\subsubsection{Función metadiscursiva}

Se centra en la estructuración del enunciado, es decir, considera los marcadores de inicio, progresión y cierre del discurso, denominados estructuradores y reformuladores. En nuestro corpus esta función se subclasifica en formulativa y reformulativa.

\subsection{Función formulativa}

Consiste en una estrategia de control del habla que permite al hablante ordenar, aclarar, precisar y reordenar su mensaje. Se subdivide en tres subfunciones:

a) Inicio: la combinación se posiciona al inicio del turno, ya que el hablante formula lo que va a decir, esto es, reflexiona antes de comenzar su intervención. Combinaciones: no sé po, nada po. Ejemplos:

11) no sé po/ decir algo que no es debido/ cosas que a uno/ uno trata de no hacer/ por lo general/ no sé po/ ser demasiado grosero (M I H113)

12) no sé po la cena/ después esperar las doce de la noche/ para abrir los regalos/ y eso es como lo más típico que se hace en todas partes (B II M026)

13) nada po volvimos a tiempo como para ver cuando los jinetes estaban pegándole a la gente y cosas por el estilo (MB I H052)

En los ejemplos anteriores, las combinaciones de po al inicio de una intervención le dan tiempo al hablante para pensar y elaborar una respuesta de modo más coherente.

b) Progresión: se posiciona al medio de un turno y ayuda a la progresión temática del discurso o como apoyo para continuarlo. Combinaciones: no sé po, sí po, ya po. Ejemplos:

14) eh como que es como más que nada esa clase de huevadas/ como que/ no sé po/ ¿cachái?/ la gente anda más apestada también po/ ¿cachái?/ me ha tocado ver alguna vieja puteada tirando chuchadas a la gente (MA I H147) 
15) I: sí/ sí porque si yo/ no sé po un ejemplo y le digo "sabe que estoy/ por decir estoy embarazada" lo sabe ella lo sabe la de acá lo sabe/ al final que saben todos/ entonces no/ no hay confianza (B I M009)

16) no se hace explícito/ pero en el fondo/ sí po/ sí igual es cierto/ igual es/ ahora uno podría decir no/ no tiene por qué darse/ porque bueno/ yo estoy interesado en que a mí me vaya bien/ sí (M I H101)

17) fue cuando estaba de gira de estudios en Brasil/ que/ tuvimos un problema con/ $\mathrm{con} /$ tuve un problema ya $\mathrm{po} / \mathrm{con} /$ que me llevaron detenido digamos/ y era bastante/ en realidad estaban bastante asustado (M I H101)

En estos ejemplos las combinaciones poseen independencia sintáctica en el enunciado y se ubican en posición intermedia entre dos actos, con el fin favorecer la progresión temática de lo dicho. También sirven como un recurso fático para cerciorarse de que el oyente está recibiendo correctamente el mensaje. De hecho, en 14, la combinación va acompañada del marcador interrogativo de control de contacto ¿cachái? (San Martín, Marcadores interrogativos, Lewis y San Martín).

c) Cierre: se ubica en posición final de un acto para concluir lo dicho. Combinaciones: no más po, ya po. Ejemplos:

18) o sea no tenemos auto/ entonces es lo que hay no más po (M I H113)

19) $\mathrm{E}: \mathrm{mm} / \mathrm{ya} / \mathrm{em} / \mathrm{bueno} / \mathrm{y}$ eso creo yo que/ es más o menos I: ya po/ muy amable (MA II H164)

En 18 la combinación no más po se ubica al final de acto para cerrar el turno y cederlo al interlocutor, mientras en 19 la combinación ya po funciona para concluir el intercambio. Por lo común, la combinación ya po acompañada de una pausa larga o de una fórmula de despedida o cortesía puede reforzar la finalización de la conversación.

\subsection{Función reformulativa}

Se utiliza para realizar un cambio temático, secuencial o para retomar la secuencia anterior a través de una precisión o aclaración por parte del hablante (Briz, El español). Combinación: ya po. Ejemplo: 
20) ee no/ que en la U de nosotros/ no se puede hacer mechoneo po/ pero sí estábamos en clases de psicología con la profe L/ un saludo para ella/ y ya po estábamos en la clase/ así súper fome/ y empezaron a golpear la puerta y a decir que saliéramos [...] mm igual te daba miedo tú sabíai que no te podían hacer nada/ por el reglamento/ pero igual daba susto/ ya estaban los cabros y te hicieron sacar una zapatilla/ pero yo no me la saqué/ porque me rehusé totalmente/ no es que tuviera una papa en el calcetín pero no quería y// ya po juntaron las zapatillas en una bolsa/ y te hacían presentar adelante y "¿de quién es esta zapatilla?" ya y el que decía "mía" tenía que salir a presentarse/ si estabai pololeando puras huevadas así [...] yo no salí y después me invitaron al R/ yo esperé a mi amiga $\mathrm{P} / /$ mi amiga de la infancia/ y ya po llegamos más tarde al R/ y ya no quedaba chela/ y tuvimos que comprar una chela nosotras/ y nos quedamos/ unas compañeras se subieron a bailar al escenario y piola/ pero nada/ así como/ “¡oh! ¡qué entretenido!” (MB I H050)

En 20 la combinación sintagmática ya po se ubica en medio de un acto y su función es retomar el tema anterior como recurso anafórico. El hablante realiza una digresión al desviarse del episodio narrado y utiliza dicha combinación para retomar el hilo narrativo en tres ocasiones. Cabe destacar que en este cometido ya po va acompañado de la conjunción $y$, la que colabora con este procedimiento reformulativo.

\subsubsection{Función modalizadora}

Se relaciona con la actitud del hablante con respecto a su enunciado. Siguiendo a Briz et al., la modalidad puede ser entendida como la actitud subjetiva del hablante relacionada con el contenido de la enunciación. Se subdivide en intensificación, atenuación, acuerdo y desacuerdo.

\subsection{Función de intensificación}

Como ya señalamos, contribuye a reforzar lo dicho por el hablante. Combinación: po huevón. Ejemplos:

21) la dura me encanta po huevón porque no lo hago po/ y yo veo a la gente apretada y me ando/ me gusta estar apretado ahí (MB II H067) 
22) I: puta como siete años/ y/ más encima mi mamá/ huevón/ falta de experiencia/ eh me puso alcohol po huevón/ en la quemadura/ me hizo más mierda la pierna (B I M010)

23) pero es que tampoco no// nunca faltó el respeto po/ nunca habló mal tampoco/ siempre fue coherente con las cosas que dice po huevón/ siempre estuvo ahí/ al medio/ al medio de todo po ¿cachái?/ entonces el loco nunca faltó po huevón/ al final el loco dice que es profesional y el loco todos sabemos que es bueno (MB I H050)

24) [...] “¿cómo no estái ahí po huevón” ¿cachái?// entonces puta/ ahí ¿cachái? empieza una cuestión de que "ah/ puta ya este huevón me dijo que me meta? ¿cachái?/ onda "ah hay gente que me quiere ahî" ¿cachái?/ después te metí más y de ahí la cosa sigue creciendo no más po (M I H147)

En estos ejemplos la partícula po se combina con el vocativo huevón (Rojas) generando un bloque que permite intensificar lo dicho anteriormente. El hablante refuerza el contenido de su enunciación con el propósito de ser claro en su discurso y convencer a su interlocutor de la certeza de lo que dice. Cabe destacar que huevón es el vocativo de confianza en el español de Chile por lo que ayuda a crear cierta complicidad con el oyente (Rojas).

\subsection{Función de atenuación}

Según Briz (El español), la atenuación está "vinculada a la relación interlocutiva, que mitiga la fuerza ilocutiva de una acción o la fuerza significativa de una palabra, de una expresión, y que puede ser explicada en una de sus funciones por el principio de cortesía" (158, destacado del autor). Consiste en una estrategia conversacional que tiene una estrecha relación con el principio de cortesía verbal entre los hablantes, aunque se trata, en rigor, de fenómenos diferentes. En este sentido, en algunas ocasiones, el hablante puede proteger la imagen positiva del oyente (ser cortés), atenuando la opinión contraria o presentado la divergencia como un falso acuerdo. Entenderemos aquí por "atenuación" la disminución de la fuerza ilocutiva de un enunciado. Combinación: no sé po. Ejemplos:

25) por el tema de las responsabilidades/ bueno y porque claro/ evidentemente eh/ una familia de alguna forma te amarra digamos/ yo creo eso// como una libertad/ pero/ yo insisto/ bueno esto es opinión digamos/ pero yo creo que más encima no sé po/ es como medio mal aprovechado (MB I H050 
Artículo. Josefa Manni, Abelardo San Martín. "Las funciones programáticas y la estratificación sociolingüística de las partículas po y pues en el habla de Santiago de Chile"

26) E: ¿y les gusta/ les gustaría participar de todas esas cosas? I: no sé po/ y depende de si me puedo los pies después (MB II H066)

En estos ejemplos la combinación no sé po rebaja la fuerza a la opinión emitida por el hablante, a fin de cuidar su imagen o la del oyente respecto de temas de naturaleza más polémica. Concordamos con el análisis de Pilleux de no sé po como un marcador discursivo de atenuación en el español de Chile en ejemplos como los precedentes.

\subsection{Función de acuerdo}

Se manifiesta cuando un hablante realiza una petición, sugerencia, pregunta o aseveración frente a la cual el oyente está de acuerdo. Siguiendo a Freites, hemos la hemos dividido en tres subfunciones: enfática, ratificación y aprobación, las que tienen en común el ser una manifestación del acuerdo por parte del interlocutor.

a) Afirmación enfática: el interlocutor responde enfáticamente frente a una pregunta, petición, sugerencia o afirmación realizada por el hablante. Así, po actúa como un reforzador del adverbio afirmativo o del marcador evidencial al que acompaña. Combinaciones: sí po, claro po. Ejemplos:

27) E: ah/ ¿todavía juega? I: sí po (B I H005)

28) E: ya/ ¿esos son los los que más recordái con/ más// lo que le dai más importancia? I: sí po (B I H001)

29) E: ¿y usa algún medio de transporte? I: claro po (MB III H083)

En los ejemplos sí po se encuentra al inicio de acto y consiste en una construcción sintagmática independiente que sirve como respuesta afirmativa intensificada. De modo semejante ocurre también con la combinación claro po en la que po intensifica el valor evidencial de claro.

b) Ratificación: posee una función fática de control de contacto, ya que el interlocutor le ratifica al hablante que ha recibido correctamente el mensaje y que está 
prestando atención a su discurso. Así, su respuesta solo le confirma al hablante que puede proseguir con su intervención. Combinación: sí po. Ejemplos:

30) E: es porque ahora somos todos como/ ahora somos todos diferentes po ¿cachái? I: sí po E: y cada uno tiene distintos intereses y cosas así po (MB I H050)

31)E: yo llego en la mañana po I: sí po E: temprano para que tengái más tiempo (MB I H050)

32) E: hace que uno vaya I: sí po E: teniendo sensibilidades especiales// ahora vamos a hablar de otros fenómenos extraños (B II M025)

En los ejemplos anteriores se puede apreciar que el marcador discursivo sí po aparece al inicio del acto y es utilizado por el informante como una intervención para que el entrevistador continúe con su turno.

c) Aprobación: se basa en una respuesta afirmativa por parte del oyente, pero a diferencia de la ratificación, el oyente al realizar la intervención sí toma el turno en el intercambio. Combinaciones: sí po, claro po. Ejemplos:

33) E: ¿y ha pensado que haría si se gana el premio mayor o el premio que está acumulado? I: sí po no es que lo haya pensado/ sino que lo sueño los sueños son los que hacen a uno participar de estos juegos de azar po/ como por ejemplo em conocer disfrutar (M III H132)

34) E: ¿y te gustaría algún día/ volver a/ terminar el colegio o no? I: claro po/ claro que sí/ pero más adelante eso sí po (B I M011)

35) E: ¿también? I: claro po/ pero no tuve un buen resultado de ese (MB II H069)

Como se desprende de estos ejemplos, el informante no solo responde afirmativamente a la pregunta del entrevistador, sino que mediante las combinaciones formula o elabora una respuesta más extensa. A nuestro juicio, puede afirmarse que sí po y claro po están altamente gramaticalizadas en español de Chile dada su alta frecuencia en el corpus que analizamos. 
Artículo. Josefa Manni, Abelardo San Martín. "Las funciones programáticas y la estratificación sociolingüística de las partículas po y pues en el habla de Santiago de Chile"

\subsection{Función de desacuerdo}

Se relaciona con la desaprobación por parte del oyente de lo dicho anteriormente por el hablante. Ante una pregunta u opinión del hablante, el interlocutor la desaprueba con una respuesta simple o una formulación que le permita justificar su punto de vista. Combinación: no po. Ejemplos:

36) E: no/ lo bueno es que cada vecino se/ se avisaba en caso de peligro po I: $j \mathrm{ah} /$ no po! pero eso fue ya después cuando [...] (MB II H068)

37)E: sí po/ y ahora que estái trabajando que salí para fuera/ ¿lo tomái de repente como que son vacaciones?/ ¿o no? I.: no pol que no no son vacaciones po/ porque adonde salgo a vender yo/ salgo a vender mi producto/ me dedico más a trabajar a hacer plata// pero igual conozco po/ he estado casi en/ casi conozco todo Chile ya po (B II M028)

38)E: pero ¿qué? ¿qué?/ ¿te asalto? I: no po/ me pescó del cuello y me la puso en la espalda E: pero ¿qué quería? ¿monedas o era porque era/? I: ¡no po! que me fuera de ahí po (MB II H068)

39) I: ah/ pero como anécdota no te conté ninguna po E: no porque dijo que I: no po como anécdota tengo muchas en mi vida po/ es que no sé po como cuál te podría contar una anécdota asíl/ ah/ ¿te cuento una anécdota? (MB III H082)

En los ejemplos se puede observar que el oyente responde con un adverbio de negación no que es intensificado por la partícula discursiva po. En nuestra opinión, así como ocurre con sí po y claro po, la combinación sintagmática no po está en franco proceso de gramaticalización en el español de Chile, ya que casi la totalidad de los desacuerdos en nuestro corpus se manifestaron con no po, mientras que no simple se dio en muy pocas ocasiones.

La siguiente tabla resume los resultados de las funciones particulares de las combinaciones sintagmáticas analizadas en nuestro corpus:

\begin{tabular}{|c|c|c|c|}
\hline \multicolumn{2}{|c|}{ Funciones } & Partícula & Posición \\
\hline \multirow{4}{*}{$\begin{array}{c}\text { Función } \\
\text { metadiscursiva }\end{array}$} & Función formulativa & $\begin{array}{c}\text { Inicio: } \text { no sé po, nada } \\
\text { po. }\end{array}$ & $\begin{array}{c}\text { Turno inicial, } \\
\text { acto inicial. }\end{array}$ \\
\cline { 3 - 4 } & & $\begin{array}{c}\text { Progresión: } \text { no sé po, sí } \\
\text { po, ya po. }\end{array}$ & $\begin{array}{c}\text { Turno } \\
\text { intermedio }\end{array}$ \\
\cline { 3 - 4 } & & Cierre: no más po, ya & Turno de \\
\hline
\end{tabular}




\begin{tabular}{|c|c|c|c|}
\hline & & po. & $\begin{array}{l}\text { cierre, acto } \\
\text { final. }\end{array}$ \\
\hline & Función reformulativa & yа ро & $\begin{array}{c}\text { Turno } \\
\text { intermedio }\end{array}$ \\
\hline \multirow{6}{*}{$\begin{array}{c}\text { Función } \\
\text { modalizadora }\end{array}$} & Función de intensificación & po huevón & Acto final \\
\hline & Función de atenuación & no sé po & $\begin{array}{l}\text { Turno inicial, } \\
\text { inicio de acto. }\end{array}$ \\
\hline & \multirow[t]{3}{*}{ Función de acuerdo } & $\begin{array}{l}\text { Afirmación enfática: sí } \\
\text { po, claro po. }\end{array}$ & $\begin{array}{l}\text { Turno inicial, } \\
\text { inicio de acto. }\end{array}$ \\
\hline & & Ratificación: sí po. & $\begin{array}{l}\text { Turno inicial, } \\
\text { inicio de acto. }\end{array}$ \\
\hline & & $\begin{array}{l}\text { Aprobación: sí po, } \\
\text { claro po. }\end{array}$ & $\begin{array}{l}\text { Turno inicial, } \\
\text { inicio de acto. }\end{array}$ \\
\hline & Función de desacuerdo & no po & $\begin{array}{l}\text { Turno inicial, } \\
\text { inicio de acto. }\end{array}$ \\
\hline
\end{tabular}

Tabla 2: Resumen de los resultados de las funciones de las combinaciones sintagmáticas de $p o$ en el corpus

En síntesis, a partir de nuestro análisis pragmático, podemos dar cuenta de nuestras hipótesis sobre la posición y la combinación de las partículas analizadas. Así, por una parte, hemos comprobado que la posición de po y pues diferencia los valores de ambas partículas; específicamente, pues se emplea en posición inicial de acto como conector causal y final como intensificador, mientras que po se utiliza solo en posición final como intensificador. En este aspecto concordamos con lo propuesto por Briz y Pons (329): "la variación funcional de los marcadores del discurso está limitada por su posición discursiva y por el tipo de unidad en que se integran [...] la unidad y la posición están en correlación en gran medida con la función de los marcadores discursivos". Por otro lado, en contraste con pues, po se combina con otros formantes para cumplir diferentes funciones, como hemos verificado más arriba.

\subsection{Análisis sociolingüístico}

En esta sección del estudio presentaremos los resultados del análisis sociolingüístico de las frecuencias de las partículas po y pues, así como de las combinaciones sintagmáticas de la primera de ellas, en relación con los factores sociales género, edad y grupo socioeconómico de los sujetos de la muestra. En primer lugar, previamente a acometer 
Artículo. Josefa Manni, Abelardo San Martín. "Las funciones programáticas y la estratificación sociolingüística de las partículas po y pues en el habla de Santiago de Chile"

dicha correlación, nos referiremos a las frecuencias generales de empleo de po y pues en el corpus. En nuestros materiales relevamos un total de 5639 casos de los cuales $5560(97,7 \%)$ corresponden a po y 133 (2,3\%) a pues; por lo tanto, como cabría esperar, el uso de po es muy predominante, en comparación con el de pues que es bastante menos frecuente. Este hecho es coincidente con la apreciación de la intensidad del uso de la partícula po como una característica vernácula del dialecto chileno del cual el habla santiaguina puede considerarse en buena parte representativa.

\subsubsection{Estratificación social de po y pues}

A continuación, la Tabla 3 muestra los resultados generales de la distribución del empleo de po y pues en el corpus, en términos estadísticos descriptivos (frecuencias absolutas y porcentajes), en relación con las variables de género, edad y grupo socioeconómico de los informantes.

\begin{tabular}{|l|c|c|c|c|}
\hline \multirow{2}{*}{} & \multicolumn{2}{|c|}{ po } & \multicolumn{2}{c|}{ pues } \\
\cline { 2 - 5 } & $\mathbf{N}$ & $\mathbf{\%}$ & $\mathbf{N}$ & $\mathbf{\%}$ \\
\hline Mujeres & 2715 & 48,8 & 38 & 28,6 \\
\hline Hombres & 2845 & 51,2 & 95 & 71,4 \\
\hline $20-34$ & 2344 & 42,2 & 1 & 0,8 \\
\hline $35-54$ & 1774 & 32 & 84 & 63,2 \\
\hline 55 o más & 1442 & 25,8 & 48 & 36 \\
\hline Bajo & 2063 & 37,1 & 116 & 87,2 \\
\hline $\begin{array}{l}\text { Medio } \\
\text { bajo }\end{array}$ & 2151 & 38,7 & 10 & 7,5 \\
\hline Medio & 601 & 10,8 & 6 & 4,5 \\
\hline $\begin{array}{l}\text { Medio } \\
\text { alto }\end{array}$ & 745 & 13,4 & 1 & 0,8 \\
\hline Total & 5560 & 100 & 133 & 100 \\
\hline
\end{tabular}

Tabla 3: Frecuencias absolutas y porcentajes de po y pues según los factores sociales de los sujetos 
Como puede apreciarse, con respecto al género de los informantes, el uso de po es bastante igualitario, pero el de pues es más predominante en los hombres de la muestra. En cuanto a las diferencias etarias, mientras el empleo de po es más frecuente en los jóvenes y decrece a medida que avanza la edad de los sujetos, el de pues se concentra en el grupo adulto al que le sigue el de mayor edad sin casi manifestarse en el juvenil. Finalmente, por lo que refiere al contraste entre los grupos socioeconómicos, el uso de po es más intenso en los informantes de los grupos medio bajo y bajo, pero lo es mucho menos en los del medio alto y medio; asimismo, pues es definitivamente más frecuente en los sujetos del grupo bajo, ya que su ocurrencia en los demás grupos es muy escasa.

En lo que sigue, la Tabla 4 proporciona los resultados de las pruebas de estadística inferencial paramétrica y no paramétrica, ANOVA y Kruskal-Wallis, respectivamente, que hemos aplicado a las frecuencias de uso general de po y pues, a efecto de medir su eventual asociación con las variables sociodemográficas antes señaladas.

\begin{tabular}{|c|c|c|c|c|c|c|c|c|c|c|c|c|}
\hline & \multicolumn{6}{|c|}{ po } & \multicolumn{6}{|c|}{ pues } \\
\hline & \multicolumn{3}{|c|}{ ANOVA } & \multicolumn{3}{|c|}{ Kruskal-Wallis } & \multicolumn{3}{|c|}{ ANOVA } & \multicolumn{3}{|c|}{ Kruskal-Wallis } \\
\hline & $\begin{array}{l}\text { Med } \\
\text { ias }\end{array}$ & $\mathrm{F}$ & $\mathrm{p}$ & $\begin{array}{l}\text { Ran } \\
\text { gos }\end{array}$ & $\mathrm{Chi}^{2}$ & $\mathrm{p}$ & $\begin{array}{l}\text { Med } \\
\text { ias }\end{array}$ & $\mathrm{F}$ & $\mathrm{p}$ & $\begin{array}{l}\text { Ran } \\
\text { gos }\end{array}$ & $\mathrm{Chi}^{2}$ & $\mathrm{p}$ \\
\hline $\begin{array}{l}\text { Mujere } \\
\text { s }\end{array}$ & $\begin{array}{l}45,2 \\
5\end{array}$ & $\begin{array}{l}0,07 \\
1\end{array}$ & $\begin{array}{l}0,79 \\
0\end{array}$ & $\begin{array}{l}60,6 \\
8\end{array}$ & $\begin{array}{l}0,00 \\
3\end{array}$ & $\begin{array}{l}0,95 \\
4\end{array}$ & 0,63 & $\begin{array}{l}0,48 \\
1\end{array}$ & $\begin{array}{l}0,48 \\
9\end{array}$ & $\begin{array}{l}58,0 \\
8\end{array}$ & $\begin{array}{l}1,58 \\
8\end{array}$ & $\begin{array}{l}0,20 \\
8\end{array}$ \\
\hline $\begin{array}{l}\text { Hombr } \\
\text { es }\end{array}$ & $\begin{array}{l}77,4 \\
2\end{array}$ & & & $\begin{array}{l}60,3 \\
2\end{array}$ & & & 1,58 & & & $\begin{array}{l}62,9 \\
3\end{array}$ & & \\
\hline $20-34$ & $\begin{array}{l}58,6 \\
0\end{array}$ & $\begin{array}{l}2,72 \\
2\end{array}$ & $\begin{array}{l}0,07 \\
0\end{array}$ & $\begin{array}{l}68,8 \\
3\end{array}$ & $\begin{array}{l}3,61 \\
3\end{array}$ & $\begin{array}{l}0,16 \\
4\end{array}$ & 0,03 & $\begin{array}{l}0,77 \\
0\end{array}$ & $\begin{array}{l}0,46 \\
5\end{array}$ & & $\begin{array}{l}5,00 \\
7\end{array}$ & $\begin{array}{l}0,07 \\
9\end{array}$ \\
\hline $35-54$ & $\begin{array}{l}44,3 \\
5\end{array}$ & & & $\begin{array}{l}57,9 \\
6\end{array}$ & & & 2,10 & & & $\begin{array}{l}60,7 \\
6\end{array}$ & & \\
\hline $\begin{array}{ll}55 & \text { o } \\
\text { más } & \end{array}$ & $\begin{array}{l}36,0 \\
5\end{array}$ & & & $\begin{array}{l}54,7 \\
1\end{array}$ & & & 1,20 & & & $\begin{array}{l}65,6 \\
8\end{array}$ & & \\
\hline Bajo & $\begin{array}{l}69,0 \\
33\end{array}$ & $\begin{array}{l}16,7 \\
40\end{array}$ & $\begin{array}{l}0,00 \\
0\end{array}$ & $\begin{array}{l}76,3 \\
2\end{array}$ & $\begin{array}{l}34,2 \\
34\end{array}$ & $\begin{array}{l}0,00 \\
0\end{array}$ & 3,87 & $\begin{array}{l}1,85 \\
8\end{array}$ & $\begin{array}{l}0,14 \\
1\end{array}$ & & $\begin{array}{l}5,68 \\
1\end{array}$ & $\begin{array}{l}0,12 \\
8\end{array}$ \\
\hline Medio & 71,7 & & & 81,5 & & & 0,33 & & & 59,8 & & \\
\hline
\end{tabular}


Artículo. Josefa Manni, Abelardo San Martín. "Las funciones programáticas y la estratificación sociolingüística de las partículas po y pues en el habla de Santiago de Chile"

\begin{tabular}{|c|c|c|c|c|}
\hline \multirow{2}{*}{$\begin{array}{l}\text { bajo } \\
\text { Medio }\end{array}$} & 00 & 3 & \multirow[b]{2}{*}{0,20} & \multirow{3}{*}{\begin{tabular}{|l|}
7 \\
57,9 \\
5 \\
\end{tabular}} \\
\hline & 20,0 & 40,0 & & \\
\hline & 33 & 0 & & \\
\hline Medio & 23,3 & 44,1 & 0,03 & 56,0 \\
\hline alto & 00 & 5 & & 8 \\
\hline
\end{tabular}

Tabla 4: Resultados de las pruebas estadísticas aplicadas a po y pues según los factores sociales de los sujetos

Tal como refleja la tabla, solo se encontraron datos con significación estadística (valor de p) para po, no para pues; específicamente, relevamos una coincidencia entre los estadígrafos significativos, tanto paramétrico como no paramétrico, de la asociación entre el grupo socioeconómico de los hablantes y el uso de po. El Gráfico 1 ilustra las diferencias entre dichos grupos en el empleo de la mencionada partícula.

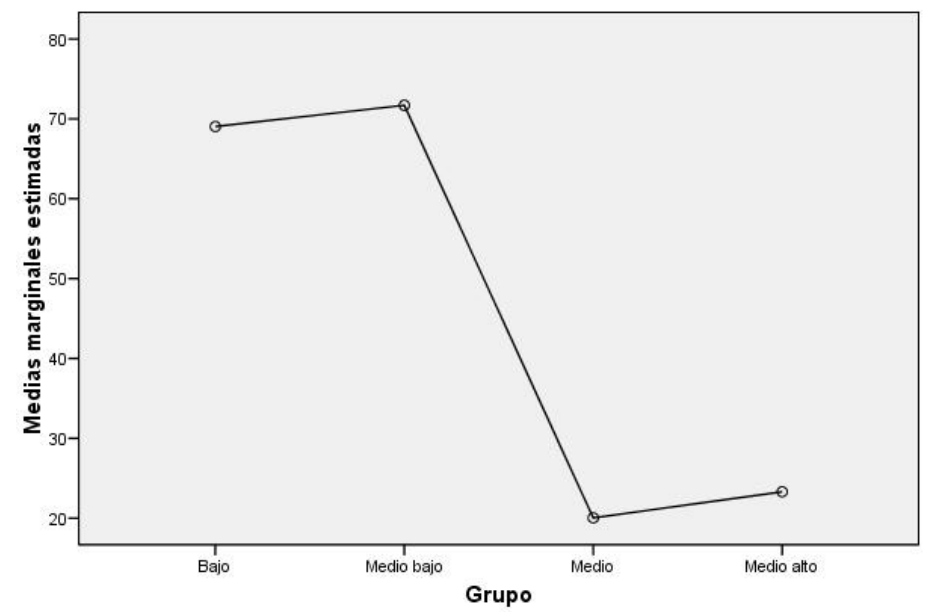

Gráfico 1: Medias de empleo general de po según el grupo socioeconómico de los sujetos

De acuerdo con nuestros datos, podemos comprobar una relación entre el uso de po y los grupos socioeconómicos de los hablantes, puesto que es mucho más frecuente en los grupos medio bajo y bajo, en comparación con su ocurrencia en los grupos medio alto y medio. De este modo, se configura un "patrón de estratificación abrupta o discontinua" (Moreno Fernández 77), en el que se aprecia una clara separación entre ambos extremos del espectro, que es más frecuente en la variación socio-gramatical (81). Este hallazgo también es coincidente con la valoración de po como un rasgo del dialecto vernáculo chileno, puesto que da cuenta de su carácter lingüístico más popular; no obstante, como es obvio, de este resultado no puede colegirse que la partícula po no se emplee por hablantes de los grupos 
socioeconómicos superiores, sino que aquí damos cuenta solo de una mayor intensidad en su uso por parte de los hablantes de los grupos inferiores.

\subsubsection{Estratificación social de las combinaciones sintagmáticas de po}

En nuestros materiales, del total de casos de po (5560), en $3264(58,7 \%)$ ocasiones esta partícula no se combinó con otros formantes (adverbios, vocativos, locuciones u otros marcadores) recurrentes, mientras que en 2296 (41,3\%) casos sí lo hizo. A su vez, del total de ocurrencias con combinación antes indicado, registramos las siguientes frecuencias absolutas y porcentajes de combinaciones sintagmáticas en orden decreciente: sí po 719 (31,3\%), no sé po 550 (24\%), no po 337 (14,7\%), no más po 183 (8\%), po huevón 149 (6,4\%), nada po 124 (5,4\%), ya po $120(5,2 \%)$ y claro po $114(5 \%)$. Por consiguiente, la más frecuente es sí po con más de un cuarto de las ocurrencias, seguida de no sé po y no po; el resto de las combinaciones se da en porcentajes inferiores al $10 \%$.

La Tabla 5, a continuación, muestra la distribución de casos de cada una de estas combinaciones en relación con las variables sociales género, edad y grupo socioeconómico de los informantes de la muestra, en términos estadísticos descriptivos.

\begin{tabular}{|c|c|c|c|c|c|c|c|c|c|c|c|c|c|c|c|c|}
\hline & \multicolumn{2}{|c|}{ no sé po } & \multicolumn{2}{|c|}{ nada po } & \multicolumn{2}{|c|}{ sípo } & \multicolumn{2}{|c|}{ уа ро } & \multicolumn{2}{|c|}{ по ро } & \multicolumn{2}{|c|}{$\begin{array}{c}\text { no más } \\
\text { po }\end{array}$} & \multicolumn{2}{|c|}{ claro po } & \multicolumn{2}{|c|}{$\begin{array}{c}\text { po } \\
\text { huevón }\end{array}$} \\
\hline & $\mathrm{N}$ & $\%$ & $\mathrm{~N}$ & $\%$ & $\mathrm{~N}$ & $\%$ & $\mathrm{~N}$ & $\%$ & $\mathrm{~N}$ & $\%$ & $\mathrm{~N}$ & $\%$ & $\mathrm{~N}$ & $\%$ & $\mathrm{~N}$ & $\%$ \\
\hline $\begin{array}{l}\text { Mujer } \\
\text { es }\end{array}$ & $\begin{array}{l}24 \\
3\end{array}$ & $\begin{array}{l}44, \\
2\end{array}$ & 65 & $\begin{array}{l}52, \\
4\end{array}$ & $\begin{array}{l}35 \\
2\end{array}$ & 49 & 69 & $\begin{array}{l}57, \\
5\end{array}$ & $\begin{array}{l}17 \\
9\end{array}$ & $\begin{array}{l}53, \\
1\end{array}$ & 81 & $\begin{array}{l}44, \\
3\end{array}$ & 52 & $\begin{array}{l}45, \\
6\end{array}$ & 17 & $\begin{array}{l}11, \\
4\end{array}$ \\
\hline $\begin{array}{l}\text { Homb } \\
\text { res }\end{array}$ & $\begin{array}{l}30 \\
7\end{array}$ & $\begin{array}{l}55, \\
8\end{array}$ & 59 & $\begin{array}{l}47, \\
6\end{array}$ & $\begin{array}{l}36 \\
7\end{array}$ & 51 & 51 & $\begin{array}{l}42, \\
5\end{array}$ & $\begin{array}{l}15 \\
8\end{array}$ & $\begin{array}{l}46, \\
9\end{array}$ & $\begin{array}{l}10 \\
2\end{array}$ & $\begin{array}{l}55, \\
7\end{array}$ & 62 & $\begin{array}{l}54, \\
4\end{array}$ & $\begin{array}{l}13 \\
2\end{array}$ & $\begin{array}{l}88, \\
6\end{array}$ \\
\hline $20-34$ & $\begin{array}{l}27 \\
9\end{array}$ & $\begin{array}{l}50, \\
7\end{array}$ & $\overline{65}$ & $\begin{array}{l}52, \\
4\end{array}$ & $\begin{array}{l}26 \\
4\end{array}$ & $\begin{array}{l}36, \\
7\end{array}$ & 51 & $\begin{array}{l}42, \\
5\end{array}$ & $\begin{array}{l}11 \\
9\end{array}$ & $\begin{array}{l}35, \\
3\end{array}$ & 58 & $\begin{array}{l}31, \\
7\end{array}$ & 76 & $\begin{array}{l}66, \\
6\end{array}$ & $\begin{array}{l}13 \\
1\end{array}$ & $\begin{array}{l}87, \\
9\end{array}$ \\
\hline $35-54$ & $\begin{array}{l}20 \\
2\end{array}$ & $\begin{array}{l}36, \\
7\end{array}$ & 34 & $\begin{array}{l}27, \\
4\end{array}$ & $\begin{array}{l}28 \\
6\end{array}$ & $\begin{array}{l}39, \\
8\end{array}$ & 44 & $\begin{array}{l}36, \\
7\end{array}$ & $\begin{array}{l}10 \\
5\end{array}$ & $\begin{array}{l}31, \\
2\end{array}$ & 66 & $\begin{array}{l}36, \\
1\end{array}$ & 15 & $\begin{array}{l}13, \\
2\end{array}$ & 4 & 2,7 \\
\hline $\begin{array}{ll}55 \quad \text { o } \\
\text { más }\end{array}$ & 69 & $\begin{array}{l}12, \\
6\end{array}$ & 25 & $\begin{array}{l}20, \\
2\end{array}$ & $\begin{array}{l}16 \\
9\end{array}$ & $\begin{array}{l}23, \\
5\end{array}$ & 25 & $\begin{array}{l}20, \\
8\end{array}$ & $\begin{array}{l}11 \\
3\end{array}$ & $\begin{array}{l}33, \\
5\end{array}$ & 59 & $\begin{array}{l}32, \\
2\end{array}$ & 23 & $\begin{array}{l}20, \\
2\end{array}$ & 14 & 9,4 \\
\hline
\end{tabular}


Artículo. Josefa Manni, Abelardo San Martín. "Las funciones programáticas y la estratificación sociolingüística de las partículas po y pues en el habla de Santiago de Chile"

\begin{tabular}{|c|c|c|c|c|c|c|c|c|c|c|c|c|c|c|c|c|}
\hline $\bar{B}$ & $\begin{array}{l}13 \\
5\end{array}$ & $\begin{array}{l}24, \\
5\end{array}$ & 46 & $\begin{array}{l}37, \\
1\end{array}$ & $\begin{array}{l}31 \\
0\end{array}$ & $\begin{array}{l}43, \\
1\end{array}$ & 47 & $\begin{array}{l}39, \\
2\end{array}$ & $\begin{array}{l}13 \\
9\end{array}$ & $\begin{array}{l}41, \\
3\end{array}$ & 79 & $\begin{array}{l}43, \\
1\end{array}$ & 36 & $\begin{array}{l}31, \\
6\end{array}$ & 55 & $\begin{array}{l}36, \\
9\end{array}$ \\
\hline MB & $\begin{array}{l}17 \\
3\end{array}$ & $\begin{array}{l}31, \\
5\end{array}$ & 51 & $\begin{array}{l}41, \\
1\end{array}$ & $\begin{array}{l}26 \\
2\end{array}$ & $\begin{array}{l}36, \\
4\end{array}$ & 36 & $\begin{array}{l}29, \\
9\end{array}$ & $\begin{array}{l}14 \\
4\end{array}$ & $\begin{array}{l}42, \\
7\end{array}$ & 60 & $\begin{array}{l}32, \\
8\end{array}$ & 50 & $\begin{array}{l}43, \\
9\end{array}$ & 83 & $\begin{array}{l}55, \\
7\end{array}$ \\
\hline $\mathrm{M}$ & 98 & $\begin{array}{l}17, \\
8\end{array}$ & 8 & 6,5 & 82 & $\begin{array}{l}11, \\
4\end{array}$ & 29 & $\begin{array}{l}24, \\
2\end{array}$ & 31 & 9,2 & 8 & 4,4 & 8 & 7 & 6 & 4 \\
\hline MA & $\begin{array}{l}14 \\
4\end{array}$ & $\begin{array}{l}26, \\
2\end{array}$ & 19 & $\begin{array}{l}15, \\
3\end{array}$ & 65 & 9,1 & 8 & 6,7 & 23 & 6,8 & 36 & $\begin{array}{l}19, \\
7\end{array}$ & 20 & $\begin{array}{l}17, \\
5\end{array}$ & 5 & 3,4 \\
\hline $\begin{array}{l}\text { Totale } \\
\text { s }\end{array}$ & $\begin{array}{l}55 \\
0\end{array}$ & $\begin{array}{l}10 \\
0\end{array}$ & $\begin{array}{l}12 \\
4\end{array}$ & $\begin{array}{l}10 \\
0\end{array}$ & $\begin{array}{l}71 \\
9\end{array}$ & $\begin{array}{l}10 \\
0\end{array}$ & $\begin{array}{l}12 \\
0\end{array}$ & $\begin{array}{l}10 \\
0\end{array}$ & $\begin{array}{l}33 \\
7\end{array}$ & $\begin{array}{l}10 \\
0\end{array}$ & $\begin{array}{l}18 \\
3\end{array}$ & $\begin{array}{l}10 \\
0\end{array}$ & $\begin{array}{l}11 \\
4\end{array}$ & $\begin{array}{l}10 \\
0\end{array}$ & $\begin{array}{l}14 \\
9\end{array}$ & $\begin{array}{l}10 \\
0\end{array}$ \\
\hline
\end{tabular}

Tabla 5: Frecuencias absolutas y porcentajes de las combinaciones sintagmáticas de po según los factores sociales de los sujetos

De la tabla se desprende que, en cuanto al género, las combinaciones nada po, ya po y no po se dan más en el discurso de las mujeres, mientras que no sé po, sí po, nomás po, claro po y po huevón lo hacen en el de los hombres. No obstante, las diferencias de género no son muy marcadas, en general, a excepción de po huevón que descriptivamente es una combinación más masculina. Por lo que refiere a los grupos etarios, no sé po, nada po, ya po, no po, claro po у ро huevón son más frecuentes en los informantes jóvenes de la muestra, a la vez que sí po y no más po lo son en los sujetos adultos de edad intermedia. En ninguna de las combinaciones se da un uso más marcado en informantes de mayor edad. Con todo, solo en las combinaciones po huevón, claro po, nada po y no sé po pueden apreciarse diferencias etarias más marcadas. Con respecto a los grupos socioeconómicos, las combinaciones no sé po, nada po, no po, claro po y po huevón son más frecuentes en los sujetos del grupo medio bajo, mientras sí po, ya po y no más po lo son en los del grupo bajo. Los porcentajes de empleo de las combinaciones en los informantes de los grupos medio y medio alto son bastante menores y solo el de no sé po en el medio alto supera el $25 \%$.

En lo que sigue, informaremos los resultados de la aplicación de las pruebas de estadística inferencial paramétrica (ANOVA) y no paramétrica (Kruskal-Wallis) a las frecuencias de uso de las combinaciones sintagmáticas de po, en relación con las variables 
sociodemográficas. Por motivos de espacio, solo reportaremos los datos de las combinaciones en que hayamos comprobado índices de significación estadística coincidentes entre ambas pruebas. Por un lado, la Tabla 6 muestra los indicadores estadísticos de las combinaciones sintagmáticas vinculadas con la edad de los hablantes.

\begin{tabular}{|l|l|l|l|l|l|l|l|l|l|l|}
\hline \multirow{2}{*}{$\begin{array}{l}\text { Combina } \\
\text { ción }\end{array}$} & \multicolumn{3}{|c|}{ Medias } & \multicolumn{3}{|c|}{ ANOVA } & \multicolumn{3}{c|}{ Rangos } & \multicolumn{2}{|c|}{$\begin{array}{l}\text { Kruskal- } \\
\text { Wallis }\end{array}$} \\
\cline { 2 - 11 } & $\begin{array}{l}20- \\
34\end{array}$ & $\begin{array}{l}35- \\
54\end{array}$ & $\begin{array}{l}55 \\
\text { más }\end{array}$ & F & p & $\begin{array}{l}20- \\
34\end{array}$ & $\begin{array}{l}35- \\
54\end{array}$ & $\begin{array}{l}55 \\
\text { más }\end{array}$ & Chi $^{2}$ & $\mathrm{p}$ \\
\hline no sé po & 6,97 & 5,05 & 1,725 & 6,66 & 0,00 & 76,5 & 60,3 & 44,64 & 17,3 & 0,00 \\
& 5 & 0 & & 3 & 2 & 1 & 5 & & 41 & 2 \\
\hline po & 3,27 & 0,10 & 0,350 & 3,72 & 0,02 & 68,7 & 57,6 & 55,09 & 11,2 & 0,00 \\
huevón & 5 & 0 & & 4 & 7 & 6 & 5 & & 43 & 4 \\
\hline
\end{tabular}

Tabla 6: Resultados de las pruebas aplicadas a las combinaciones sintagmáticas de po con significación estadística según la edad de los sujetos

Como puede apreciarse, las combinaciones no sé po y po huevón son empleadas mayormente por hablantes del grupo etario más joven con un contraste entre medias de uso bastante marcado. Por otra parte, la Tabla 7 presenta la información estadística de las combinaciones sintagmáticas asociadas con el grupo socioeconómico de los hablantes.

\begin{tabular}{|c|c|c|c|c|c|c|c|c|c|c|c|c|}
\hline \multirow[t]{2}{*}{$\begin{array}{c}\text { Combina } \\
\text { ción }\end{array}$} & \multicolumn{4}{|c|}{ Medias } & \multicolumn{2}{|c|}{ ANOVA } & \multicolumn{4}{|c|}{ Rangos } & \multicolumn{2}{|c|}{$\begin{array}{c}\text { Kruskal- } \\
\text { Wallis }\end{array}$} \\
\hline & B & MB & M & MA & $\mathrm{F}$ & $\mathrm{p}$ & B & MB & M & MA & $\mathrm{Chi}^{2}$ & $\mathrm{p}$ \\
\hline \multirow[t]{2}{*}{ sípo } & 10,3 & 8,73 & 2,73 & 2,16 & 10,3 & 0,00 & 80,5 & 73,8 & 48,2 & 39,3 & 29,6 & 0,00 \\
\hline & 33 & 3 & 3 & 7 & 83 & 0 & 7 & 8 & 0 & 5 & 31 & 0 \\
\hline \multirow[t]{2}{*}{ no po } & 4,63 & 4,80 & 1,03 & 0,76 & 13,0 & 0,00 & 75,1 & 84,3 & 40,3 & 42,1 & 40,0 & 0,00 \\
\hline & 3 & 0 & 3 & 7 & 82 & 0 & 8 & 5 & 7 & 0 & 40 & 0 \\
\hline \multirow[t]{2}{*}{ ya po } & 1,56 & 1,20 & 0,96 & 0,26 & 3,06 & 0,03 & 73,8 & 65,3 & 56,7 & 46,0 & 12,8 & 0,00 \\
\hline & 7 & 0 & 7 & 7 & 2 & 1 & 8 & 3 & 2 & 7 & 54 & 5 \\
\hline no más & 2,63 & 2,00 & 0,26 & 1,20 & 7,57 & 0,00 & 73,4 & 72,3 & 36,6 & 59,5 & 24,4 & 0,00 \\
\hline po & 3 & 0 & 7 & 0 & 0 & 0 & 3 & 7 & 5 & 5 & 04 & 0 \\
\hline
\end{tabular}


Artículo. Josefa Manni, Abelardo San Martín. "Las funciones programáticas y la estratificación sociolingüística de las partículas po y pues en el habla de Santiago de Chile"

\begin{tabular}{|l|l|l|l|l|l|l|l|l|l|l|l|l|}
\hline nada po & 1,53 & 1,70 & 0,26 & 0,63 & 2,69 & 0,04 & 66,7 & 72,5 & 49,6 & 53,0 & 12,1 & 0,00 \\
& 3 & 0 & 7 & 3 & 6 & 9 & 7 & 7 & 3 & 3 & 69 & 7 \\
\hline
\end{tabular}

Tabla 7: Resultados de las pruebas aplicadas a las combinaciones sintagmáticas de po con significación estadística según el grupo socioeconómico de los sujetos

De acuerdo con nuestro análisis, comprobamos una mayor frecuencia de uso de las combinaciones sí po, ya po y no más po en los hablantes del grupo bajo y de no po y nada po en los del medio bajo, la que es concordante con el patrón abrupto del empleo general de po que reportamos más arriba (Gráfico 1). Así, por lo que refiere a las combinaciones antes señaladas, también puede inferirse un mayor contraste entre las medias de empleo de los grupos inferiores (bajo y medio bajo) y la de los superiores (medio y medio alto) del espectro.

Para complementar esta sección, hemos creído pertinente reportar los estadígrafos de po sin combinar que también presentan una significación coincidente en ambas pruebas (ANOVA, F= 13,291 y p= 0,000; Kruskal-Wallis, Chi-cuadrado=30,229 y p=0,000) en su asociación con el grupo socioeconómico de los hablantes. Las medias correspondientes son las siguientes: 40,533 (Bajo), 43,067 (Medio bajo), 11,033 (Medio) y 14,167 (Medio alto); a su vez, los rangos promedios son: 73,48 (Bajo), 81,77 (Medio bajo), 41,08 (Medio) y 45,67 (Medio alto). Tal como se desprende del Gráfico 2, a continuación, el patrón abrupto de las medias generales de po se repite en el caso específico de po sin combinar.

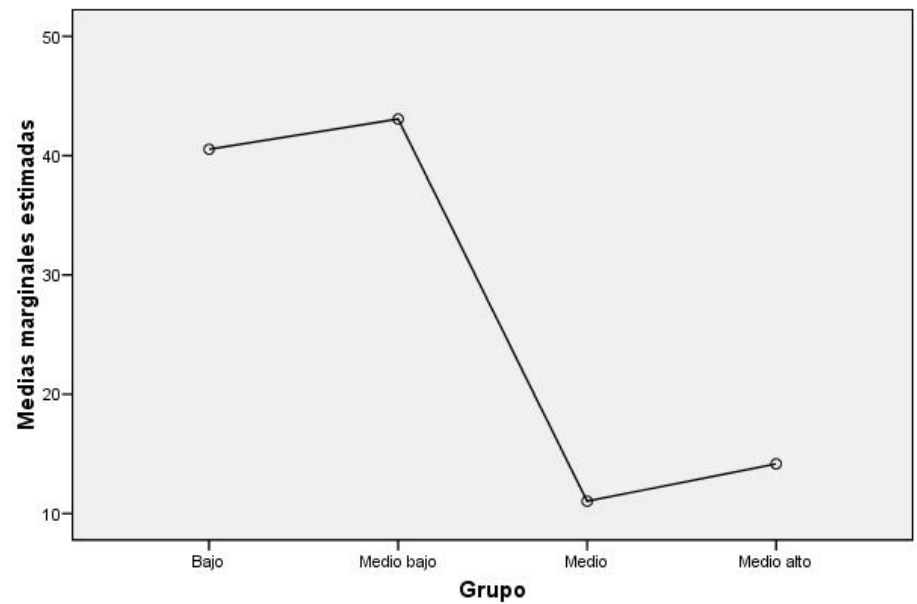

Gráfico 2: Medias de empleo de po sin combinar según el grupo socioeconómico de los sujetos 
En resumen, llegados a este punto también podemos contestar nuestras hipótesis sobre las diferencias de frecuencia de empleo entre po y pues, así como respecto de la distribución social del uso de po. De esta manera, por una parte, hemos comprobado que po se emplea mucho más que pues en la muestra y, por otra, de acuerdo con nuestro análisis sociolinguiístico, la distribución del uso de po en los factores sociales de los informantes es desigual, si bien su empleo está muy extendido en el habla santiaguina y, por extensión, chilena. En específico, de nuestros datos se desprende una fuerte asociación entre el empleo de la partícula intensificadora po y los grupos más bajos de la escala (medio bajo y bajo), en conjunto.

\section{CONCLUSIONES}

Con respecto al análisis pragmático, relevamos algunos ejemplos de la función de pues como conector causal en posición inicial, que es exclusiva de esta partícula, ya que ni este valor ni esta posición son extensibles a po. La función compartida por po y pues, sobre todo de la primera, en posición final y que es la mayoritaria en el corpus es la de partícula modal de intensificación. En dicha posición estas partículas permiten a los hablantes reafirmar sus respuestas afirmativas o negativas, reforzar sus opiniones o posturas y dotar de mayor relevancia a sus relatos. De este modo, comprobamos que la posición de ambas partículas es determinante para distinguir sus correspondientes valores. Por otro lado, verificamos que po muestra una marcada tendencia a combinarse con otras partículas, adverbios o vocativos, actuando también como coletilla intensificadora. Esta característica más versátil le permite a po asumir otras funciones en bloque con dichos acompañantes, algunas de las cuales desbordan el ámbito modal hacia el metadiscusivo, que es propio de los marcadores. Dentro de la función metadiscursiva las combinaciones sintagmáticas de po cumplen las subfunciones formulativa de inicio (no sé po, nada po), de progresión (no sé po, sí po, ya po) y de cierre (no más po, ya po), así como la subfunción reformulativa (ya po). Dentro de la función modalizadora estas combinaciones desempeñan las subfunciones de intensificación (po huevón), atenuación (no sé po), desacuerdo (no po) y acuerdo que se subdivide, a su vez, en afirmación enfática (sí po, claro po), ratificación (sí po) y aprobación (sí po, claro po). Por lo tanto, en el análisis pragmático también verificamos que las combinaciones sintagmáticas son una particularidad de po en contraste con pues. 
Artículo. Josefa Manni, Abelardo San Martín. "Las funciones programáticas y la estratificación sociolingüística de las partículas po y pues en el habla de Santiago de Chile"

Por lo que refiere al análisis sociolingüístico, nuestros datos reflejan que po se emplea mucho más que pues en la muestra y que existe una relación parcial entre las variables sociolingüísticas y ambas partículas. Desde un punto de vista descriptivo, po se emplea en ambos géneros, sin diferencias notables; en cambio, pues se emplea mayormente en el género masculino. Asimismo, pues es utilizada con mayor frecuencia por el grupo de edad adulta, mientras po es empleada por el grupo juvenil. En relación con la distribución social de las combinaciones sintagmáticas de po, en términos descriptivos, apreciamos que el grupo masculino muestra un mayor uso de po huevón, mientras que el femenino prefiere la combinación ya po. Igualmente, po huevón y no sé po son empleadas mayormente por el grupo juvenil. Además, se observó que el grupo bajo emplea con mayor frecuencia las combinaciones sí po, ya po y no más po, mientras que el grupo medio bajo se inclina por no po y nada po. Desde un punto de vista inferencial, los resultados de la aplicación de pruebas estadísticas paramétrica y no paramétrica arrojaron resultados con significación estadística solo para la asociación entre la partícula po y el grupo socioeconómico de los hablantes, la que es más empleada por los grupos medio bajo y bajo en contraste con el medio alto y medio, que muestran medias y rangos promedios mucho menores. Este dato es coincidente con la significación estadística relevada de po sin combinar que también es preferida por los hablantes de los grupos más bajos de la escala. Finalmente, las combinaciones sintagmáticas de po que mostraron resultados con significación estadística coincidente en ambas pruebas fueron no sé po y po huevón que se emplean más por los hablantes del grupo juvenil, así como sí po, no po, ya po, no más po y nada po que son más usadas por los grupos socioeconómicos medio bajo y bajo. En consecuencia, comprobamos que la distribución de po en los factores sociodemográficos de los hablantes es desigual, si bien su uso está muy extendido en el español chileno, en general. 


\section{REFERENCIAS}

Briz, Antonio. El español coloquial en la conversación. Ariel, 2001.

---. "Otra vez sobre las funciones de la intensificación en la conversación coloquial". Boletín de Filología, vol. 52, núm. 2, 2017, pp. 37-58.

Briz, Antonio, Salvador Pons y José Portolés, coordinadores. Diccionario de partículas discursivas del español (DPDE), 2008, www.dpde.es. Consultado el 10 de julio de 2018.

Briz, Antonio y Salvador Pons. "Unidades, marcadores discursivos y posición". Los estudios sobre marcadores del discurso en español, hoy. coordinación de Óscar Loureda y Esperanza Acín. Arco/Libros, 2010, pp. 327-358.

Cepeda, Gladys y María Teresa Poblete. "Marcadores conversacionales: función pragmática y expresiva". Estudios Filológicos, núm. 31, 1996, pp. 105-117.

Company, Concepción. “¿Gramaticalización o desgramaticalización? Reanálisis y subjetivización de verbos como marcadores discursivos en la historia del español". Revista de Filología Española, vol. 84, núm. 1 , 2004, pp. 29-66.

DLE $=$ Real Academia Española (RAE) y Asociación de Academias de la Lengua Española (ASALE). Diccionario de la lengua española. Espasa Calpe, 2014.

Freites, Francisco. "El marcador de discurso claro: funcionamiento pragmático, metadiscursivo y organizador de la estructura temática". Verba, núm. 33, 2006, pp. 261-27.

Fuentes Rodríguez, Catalina. Diccionario de conectores y operadores del español. Arco/Libros, 2009.

Fuentes Rodríguez, Catalina, María Elena Placencia y María Palma Fahey. "Regional pragmatic variation in the use of the discourse marker pues in informal talk among university students in Quito (Ecuador), Santiago (Chile) and Seville (Spain)". Journal of pragmatics, núm. 97, 2016, pp. 74-92.

González, Sebastián y Abelardo San Martín. "Los marcadores discursivos de relleno en el habla santiaguina: análisis pragmático y sociolingüístico". Lenguas Modernas, núm. 51, 2018, pp. 99-122.

Hernández Campoy, Juan Manuel y Manuel Almeida. Metodología de la investigación sociolingüística. Editorial Comares, 2005.

Labov, William. Modelos sociolingüísticos. Cátedra, 1983. 
Lewis, Eileen y Abelardo San Martín. “ ¿Cachái? y sus equivalentes funcionales en el habla santiaguina: análisis pragmático y sociolingüístico de los marcadores interrogativos de control de contacto”. Literatura y Lingüística, núm. 37, 2018, pp. 301-327.

Loureda, Óscar y Esperanza Acín, coordinadores. Los estudios sobre marcadores del discurso en español, hoy. Arco/Libros, 2010.

Martín Zorraquino, María. "Los marcadores del discurso y su morfología". Los estudios sobre marcadores del discurso en español, hoy, coordinación de Óscar Loureda y Esperanza Acín. Arco/Libros, 2010, pp. 93-182.

Martín Zorraquino, María y José Portolés. "Los marcadores del discurso". Gramática descriptiva de la lengua española, edición de Ignacio Bosque y Violeta Demonte. Espasa Calpe, 1999, pp. 4051-4207.

Moreno Fernández, Francisco. Principios de sociolingüística y sociología del lenguaje. Ariel, 2009.

Panussis, Constanza y Abelardo San Martín. "Como (que) y sus funciones discursivas en el habla santiaguina: análisis pragmático y sociolingüístico”. Revista de Lingüística Teórica y Aplicada, vol. 55, núm. 2, 2017, pp. 30-61.

Pilleux Mauricio. "Consideraciones acerca del marcador discursivo no sé po(h)". Onomázein, núm. 8, 2003, pp. 42-60.

Pons, Hernan y José Luis Samaniego. "Marcadores pragmáticos de apoyo discursivo en el habla culta de Santiago de Chile”. Onomázein, núm. 3, 1998, pp. 11-25.

Poblete, María Teresa. "Los marcadores discursivo-conversacionales en la construcción del texto oral”. Onomázein, núm. 2, 1997, pp. 67-81.

---. "Los marcadores discursivo-conversacionales de más alta frecuencia en el español de Valdivia (Chile)". Estudios Filológicos, núm. 33, 1998, pp. 93-103.

Portolés, José. Pragmática para hispanistas. Síntesis, 2005.

Rojas, Darío. "Huevón como marcador del discurso en el español de Chile: huellas de un proceso de gramaticalización”. Revista de Humanidades, núm. 25, 2012, pp. 143162.

Sandoval, Jorge y Abelardo San Martín. "Los modalizadores de atenuación como (que), igual, medio/a, de repente y capaz (que) en el habla santiaguina: análisis pragmático y sociolingüístico". Nueva Revista del Pacífico, núm. 72, 2020, pp. 136-162.

San Martín, Abelardo. "Los marcadores interrogativos de control de contacto en el corpus PRESEEA de Santiago de Chile”. Boletín de Filología, núm. 46, 2011, pp. 135-166. 
---. "Los marcadores de reformulación en el español oral de Santiago de Chile: análisis discursivo y sociolingüístico". Oralia, núm. 19, 2016, pp. 283-324.

---. "Marcadores discusivos y variedades del español: el español de América". Archiletras Científica, núm. IV, 2020, pp. 217-229. 